\title{
The Gas Phase HO-Initiated Oxidation of Furan: A Theoretical Investigation on the Reaction Mechanism
}

\author{
Josep M. Anglada*
}

Theoretical and Computational Chemistry Group. Departament de Química Orgànica Biològica. Institut
d'Investigacions Quimiques i Ambientals de Barcelona. IIQAB-CSIC. c/ Jordi Girona 18, E-08034 Barcelona, Spain

\begin{abstract}
The reaction mechanism of the gas-phase HO-initiated oxidation of furan has been investigated by means of high level theoretical methods. The reaction is a complex process that begins with the formation of a pre-reactive hydrogen bonded complex, previous to the addition of the $\mathrm{HO}$ radical to furan, forming the 2 and 3 -HO-adducts. In the prereactive complex, the hydrogen bond is formed by interaction between the hydrogen of the hydroxyl radical and the $\pi$ system of furan and its stability is computed to be $1.6 \mathrm{kcal} \cdot \mathrm{mol}^{-1}$ (including the BSSE corrections). The 2 and 3-HO-adducts are computed to be 30.5 and $12.5 \mathrm{kcal} \cdot \mathrm{mol}^{-1}$ respectively, more stable than the reactants. The transition state leading to the formation of the 2-HO-adduct lies below the energy of the separate reactants $\left(0.5 \mathrm{kcal} \cdot \mathrm{mol}^{-1}\right)$ and the transition state producing the 3-HO-adduct that is computed to lie $3.4 \mathrm{kcal} \cdot \mathrm{mol}^{-1}$ above the sum of the energies of furan and hydroxyl radical. There are four reaction paths for the ring-opening of the 2-HO-adduct, leading to the formation of different conformers of 4-hydroxybutenaldehyde radical. The most stable of these conformers presents a cyclic symmetric $\left(C_{2 V}\right)$ structure and can be characterized as a low-barrier hydrogen bond. The geometry optimizations and characterizations done in this work were carried out at MP2/6-311G(d,p), MP2/6-311+G(2df,2p) and QCISD/6-311G(d,p) levels of theory, whereas the relative energies are obtained at $\operatorname{CCSD}(\mathrm{T}) / \mathrm{cc}-\mathrm{pVTZ}$ level of theory.
\end{abstract}

Keywords: Furan, HO, hydrogen bonds, low-barrier hydrogen bond, gas-phase reaction mechanism, theoretical investigation.

\section{INTRODUCTION}

Furan and its derivatives are aromatic, heterocyclic organic compounds that are emitted to the troposphere from several sources including biomass burning, combustion of fossil fuels, refuse, meet cooking processes [1-5], and are also formed by oxidation or photooxidation of hydrocarbons such as 1,3 butadiene, 1,3 pentadiene or isoprene [6-11]. They are therefore primary pollutants that are degraded into the atmosphere by the reactions with $\mathrm{HO}, \mathrm{O}_{3}, \mathrm{NO}_{3}$ or by $\mathrm{Cl}$ or Br radicals [12-25], and the reaction with hydroxyl radical are the main sink in daytime.

There have been several studies regarding the reaction of furans with hydroxyl radical, studies aiming the determination of the kinetic constants and the product data. It has been suggested that the reaction occurs through the formation of an HO-adduct between furan and hydroxyl radical in the first step and undergoes an electrocyclic ring-opening process in the second step [13-15, 24]. However, there is still a lack of detailed knowledge of the reaction mechanism.

From a theoretical point of view, there are two recent works in the literature by Zhang and co-workers, dealing with the reaction mechanism of the reaction of HO with 2Methylfuran and with 3-Methylfuran, respectively [26, 27].

*Address correspondence to this author at the Theoretical and Computational Chemistry Group. Departament de Química Orgànica Biològica. Institut d'Investigacions Químiques i Ambientals de Barcelona. IIQAB CSIC. c/ Jordi Girona 18, E-08034 Barcelona, Spain;

E-mail: anglada@iiqab.csic.es
Emmy and co-workers have also reported calculations on some intermediates of the HO oxidation of furan-2carboxyaldehyde and sorbitylfurfural [24, 25].

This work reports a high level theoretical study on the reaction mechanism of the $\mathrm{HO}$ initiated oxidation of furan, focusing the attention on the addition of the hydroxyl radical to the furan ring, and in the following reaction step involved the ring-opening of the HO-adduct formed.

\section{TECHNICAL DETAILS}

The geometries for all the stationary points have been optimized by using the $6-311 \mathrm{G}(\mathrm{d}, \mathrm{p})$ basis set [28], and employing the unrestricted MP2 method [29-31]. At this level of theory, we have also calculated the harmonic frequencies in order to verify the nature of the corresponding stationary points (minima or transition states) and to provide the zeropoint vibrational energy (ZPVE) and the thermodynamic contribution to the enthalpy for $\mathrm{T}=298^{\circ} \mathrm{K}$. In addition, we have done intrinsic reaction coordinate calculations in all the transition states considered, in order to check the connection with the reactants and products. Moreover, the hydrogen bonded complexes formed between furan and hydroxyl radical were also optimized and characterized, using the unrestricted MP2 method with the more flexible $6-311+G(2 d, 2 f)$ basis set. For some stationary points of interest, we have also performed geometry optimization and harmonic frequency calculations, using the unrestricted QCISD approach [32] with the $6-311 \mathrm{G}(\mathrm{d}, \mathrm{p})$ basis set. 
With the aim of getting more reliable relative energies, single point energy calculations have been performed at the optimized geometries, employing the unrestricted $\operatorname{CCSD}(\mathrm{T})$ [33-35] method. In this case, the cc-pVTZ basis set has been used [36, 37].

Moreover, we have considered the value of the T1 diagnostic $[38,39]$ of the CCSD wave function in order to assess the reliability of these calculations, with regard to the multireference character of the wave function. A better estimation of the energetic stability of the hydrogen bonded complexes found in this investigation has been obtained by taking into account the basis set superposition error (BSSE), according to the counterpoise method by Boys and Bernardi [40]. This has been computed at the $\operatorname{CCSD}(T) / c c-p V T Z$ level of theory without relaxing the molecular structure of the complexes.

The quantum chemical calculations carried out in this work were performed by using the Gaussian [41] program package. The Molden program [42] was employed to visualize the geometric and electronic features.

The bonding features of the different systems considered, were analyzed by employing the atoms in molecules (AIM) theory by Bader [43]. The topological properties of wavefunctions were computed by using the AIMPAC program package [44]. Following the AIM theory, the topological properties of a bond are characterized by the existence of a bond critical point (bcp) and the values of the electron density $\left(\rho_{\mathrm{b}}\right)$, its laplacian $\left(\nabla^{2} \rho_{\mathrm{b}}\right)$ and the energy density $(\mathrm{H}(\mathrm{r}))$ at the bcp. A bond critical point has $\nabla \rho_{b}=0$ and the laplacian of the electronic density describes two different situations. $\nabla^{2} \rho_{b}$ $<0$ indicates that the density is locally concentrated and characterizes a covalent bond. While $\nabla^{2} \rho_{b}>0$ indicates that the density is locally depleted and characterizes closed shell interactions as found in ionic bonds, hydrogen bonds, dative bonds and van der Waals interactions. For instance, a strong hydrogen bond will be associated with large values of the electron density (around 0.035 a.u.) and positive and large values of the Laplacian of the electron density (around 0.139 a.u.) at the bcp [45]. The energy density (H(r) which is the sum of the kinetic and potential energy) determines whether the accumulation of charge is stabilizing (negative values) or destabilizing (positive values), whereas the ellipticity $(\varepsilon)$ is associated with the bond isotropy, so that the values close to zero, are characteristic of single or triple bonds, while large values (i.e 0.45 ) are characteristic of double bonds [43, 4648].

\section{RESULTS AND DISCUSSION}

The reaction of furan with hydroxyl radical begins with the formation of a hydrogen bonded complex, which is named by the prefix $\mathbf{C r}$, followed by a number. The different radical minima are named by the letter $\mathbf{M}$, followed by a number and in addition, a letter is also appended to distinguish between different conformers. The transition states are named by the prefix TS, followed by the name of the minima that connects.
Table 1 contains the ZPE energies, the entropies and the relative energies, enthalpies and free energies of the minima and transition states investigated, as well as the values of the imaginary frequencies of the different transition states. The most relevant geometrical parameters of the stationary points considered in this work, are displayed in Figs. $(\mathbf{1}, \mathbf{3}, \mathbf{4 , 6}$ and 7). Figs. (2) and (5) contain a schematic profile of potential energy surfaces (PESs), whereas Scheme 1 shows a schematic picture of all conformers of 4-hydroxybutenaldehyde (M3) radical.

\section{Reactants and Pre-Reactive Hydrogen Bonded Com- plexes}

The calculations predict the existence of two hydrogen bonded complexes (CR1 and CR2), which are formed between furan and hydroxyl radical. They have been drawn in Fig. (1), along with the reactants. These species have been optimized and characterized at unrestricted MP2 level by using the $6-311 \mathrm{G}(\mathrm{d}, \mathrm{p})$ and $6-311+\mathrm{G}(2 \mathrm{df}, 2 \mathrm{p})$ basis sets and at unrestricted QCISD level with the 6-311G(d,p) basis set. The geometrical parameters obtained at MP2/6-311G(d,p) and QCISD/6-311G(d,p) levels of theory agree quite well, so that the MP2 approach describes these hydrogen bonded complexes correctly. Therefore, the best results are those obtained by optimizing unrestricted MP2 level of theory, using the more flexible $6-311+G(2 d f, 2 p)$ basis set. Fig. (1) shows that the hydrogen bonded complex CR1 has $C_{S}$ symmetry $\left({ }^{2} \mathrm{~A}\right.$ " electronic state), with the symmetry plane bisecting the furan moiety. The HO moiety lies in this plane and the hydrogen points to the centre of the furan ring. The hydrogen bond is formed by interaction between the hydrogen of the $\mathrm{HO}$ and the $\pi$ system of furan, and the dashed line in Fig. (1) represents the distance $(2.321 \AA)$ of the hydrogen to the midpoint of the axis bisecting the COC angle in the furan moiety. Similar X-H $\cdots \pi$ interactions have been recently described in the literature and have been classified as improper hydrogen bonds, showing a blue shift in their IR spectra [4951].

Fig. (1) also shows that the hydrogen bonded complex CR2 is formed by interaction between the hydrogen of the hydroxyl moiety and the oxygen of furan. It has $C_{2 V}$ symmetry $\left({ }^{2} \mathrm{~B}_{2}\right.$ electronic state), with all atoms lying in the same plane. The computed $\mathrm{O}-\mathrm{H} \cdots \mathrm{O}$ distance of the hydrogen bond is $2.028 \AA$. Besides the hydrogen bond interactions, Fig. (1) shows also that very small geometrical changes are produced in the formation of CR1 and $\mathbf{C R 2}$, relative to the separate reactants (the HO bond length is enlarged by only $0.002-$ $0.003 \AA$ in the formation of the complex; (see Fig. 1), which suggest a small stability of both complexes. In fact, the energetic results of Table 1 show that the stability of both complexes is very similar and has been computed to be 2.58 and $2.49 \mathrm{kcal}_{\mathrm{mol}} \mathrm{l}^{-1}$, respectively (BSSE corrections included).

The nature of the hydrogen bond interactions has been analyzed, according to the Atoms in Molecules (AIM) theory by Bader, with typical values of the density and the laplacian of the density at the corresponding bcp's ( $\rho=0.0102$ and 0.0174 a.u. and $\nabla^{2} \rho=0.034$ and 0.070 a.u. for $\mathbf{C R 1}$ and $\mathbf{C R 2}$ 
Table 1. Zero Point Vibrational Energies (ZPE in kcal·mol $\left.{ }^{-1}\right)$, Imaginary Frequencies (Imag, in $\left.\mathrm{cm}^{-1}\right)$, Entropies $\left(\mathrm{S}\right.$ in $\left.\mathrm{e.u}^{\mathrm{u}}\right)$ and Relative Energies $\left(\Delta \mathrm{E}\right.$ and $\Delta(\mathrm{E}+\mathrm{ZPE})$ in $\left.\mathrm{kcal} \cdot \mathrm{mol}^{-1}\right)$, Enthalpies $\left(\Delta \mathrm{H}\right.$ in $\left.\mathrm{kcal} \cdot \mathrm{mol}^{-1}\right)$ and Free Energies $\left(\Delta \mathrm{G}\right.$ in $\left.\mathrm{kcal} \cdot \mathrm{mol}^{-1}\right)$ for the Stationary Points

\begin{tabular}{|c|c|c|c|c|c|c|c|c|}
\hline Compound & Method $^{a}$ & Imag & ZPE & $\mathbf{S}$ & $\Delta \mathbf{E}^{\mathrm{b}}$ & $\Delta(\mathbf{E}+\mathrm{ZPE})^{\mathrm{b}}$ & $\Delta H(298)^{b}$ & $\Delta G(298)^{b}$ \\
\hline Furan + HO & $\begin{array}{l}\mathrm{B} / \mathrm{A} \\
\mathrm{B} / \mathrm{B} \\
\mathrm{B} / \mathrm{C}\end{array}$ & & $\begin{array}{r}49.4 \\
49.6 \\
49.5 \\
\end{array}$ & $\begin{array}{l}106.5 \\
106.2 \\
106.4 \\
\end{array}$ & $\begin{array}{l}0.00 \\
0.00 \\
0.00\end{array}$ & $\begin{array}{l}0.00 \\
0.00 \\
0.00\end{array}$ & $\begin{array}{l}0.00 \\
0.00 \\
0.00\end{array}$ & $\begin{array}{l}0.00 \\
0.00 \\
0.00\end{array}$ \\
\hline CR1 ( $\left.{ }^{2} A^{\prime \prime}\right)$ & $\begin{array}{l}\mathrm{B} / \mathrm{A} \\
\mathrm{B} / \mathrm{B} \\
\mathrm{B} / \mathrm{C}\end{array}$ & & $\begin{array}{l}50.6 \\
50.8 \\
50.6\end{array}$ & $\begin{array}{l}84.0 \\
84.5 \\
85.2\end{array}$ & $\begin{array}{c}-3.91 \\
(-2.70) \\
-4.94 \\
(-3.73) \\
-3.91 \\
(-2.73) \\
\end{array}$ & $\begin{array}{c}-2.70 \\
(-1.48) \\
-3.79 \\
(-2.58) \\
-2.78 \\
(-1.61)\end{array}$ & $\begin{array}{c}-2.79 \\
(-1.57) \\
-3.86 \\
(-2.65) \\
-2.79 \\
(-1.61)\end{array}$ & $\begin{array}{c}3.89 \\
(5.11) \\
2.62 \\
(3.84) \\
3.53 \\
(4.71) \\
\end{array}$ \\
\hline CR2 $\left({ }^{2} B_{2}\right)$ & $\begin{array}{l}\mathrm{B} / \mathrm{A} \\
\mathrm{B} / \mathrm{B} \\
\mathrm{B} / \mathrm{C}\end{array}$ & & $\begin{array}{l}50.6 \\
51.0 \\
51.0\end{array}$ & $\begin{array}{l}87.3 \\
84.8 \\
87.2\end{array}$ & $\begin{array}{c}-3.82 \\
(-2.91) \\
-4.78 \\
(-3.87) \\
-3.81 \\
(-2.94)\end{array}$ & $\begin{array}{c}-2.56 \\
(-1.65) \\
-3.41 \\
(-2.49) \\
-2.52 \\
(-1.65)\end{array}$ & $\begin{array}{c}-2.65 \\
(-1.74) \\
-3.59 \\
(-2.67) \\
-2.60 \\
(-1.73)\end{array}$ & $\begin{array}{c}3.06 \\
(3.98) \\
2.81 \\
(3.72) \\
3.12 \\
(3.99)\end{array}$ \\
\hline TSa-M1aM1b & $\mathrm{B} / \mathrm{A}$ & -207.9 & 53.0 & 72.9 & -30.20 & -26.53 & -27.93 & -17.93 \\
\hline TSb-M1aM1b & $\mathrm{B} / \mathrm{A}$ & -380.8 & 53.0 & 73.0 & -31.60 & -27.98 & -29.36 & -19.40 \\
\hline M1b & $\mathrm{B} / \mathrm{A}$ & & 53.6 & 71.2 & -33.65 & -29.46 & -30.62 & -21.01 \\
\hline TS-CR1M2a & $\begin{array}{l}\mathrm{B} / \mathrm{A} \\
\mathrm{B} / \mathrm{B}\end{array}$ & $\begin{array}{r}-808.8 \\
-529.3 \\
\end{array}$ & $\begin{array}{l}53.4 \\
51.5 \\
\end{array}$ & $\begin{array}{l}75.6 \\
76.3 \\
\end{array}$ & $\begin{array}{l}2.35 \\
1.34 \\
\end{array}$ & $\begin{array}{l}6.34 \\
3.41 \\
\end{array}$ & $\begin{array}{l}5.27 \\
2.47 \\
\end{array}$ & $\begin{array}{c}14.46 \\
11.4 \\
\end{array}$ \\
\hline M2a & $\mathrm{B} / \mathrm{A}$ & & 54.5 & 74.8 & -17.61 & -12.48 & -13.58 & -4.07 \\
\hline TSa-M2aM2b & $\mathrm{B} / \mathrm{A}$ & -265.6 & 54.0 & 73.3 & -14.80 & -10.11 & -11.45 & -1.57 \\
\hline TSb-M2aM2b & $\mathrm{B} / \mathrm{A}$ & -247.7 & 54.1 & 73.9 & -14.88 & -10.11 & -11.36 & -1.66 \\
\hline M2b & $\mathrm{B} / \mathrm{A}$ & & 54.4 & 75.8 & -15.30 & -10.25 & -11.19 & -2.07 \\
\hline M3c & $\mathrm{B} / \mathrm{A}$ & & 53.2 & 82.3 & -26.45 & -22.64 & -22.99 & -15.78 \\
\hline TS-M1b-M3d & $\mathrm{B} / \mathrm{A}$ & -782.3 & 53.2 & 73.5 & -14.95 & -11.14 & -12.45 & -2.62 \\
\hline M3d & $\mathrm{B} / \mathrm{A}$ & & 53.6 & 78.8 & -34.11 & -29.91 & -30.47 & -22.2 \\
\hline M3e & $\mathrm{B} / \mathrm{A}$ & & 53.4 & 80.1 & -34.14 & -30.15 & -3061 & -22.75 \\
\hline M3f & $\mathrm{B} / \mathrm{A}$ & & 53.3 & 79.8 & -30.40 & -26.49 & -27.01 & -19.07 \\
\hline M3g & $\mathrm{B} / \mathrm{A}$ & & 53.1 & 80.2 & -34.56 & -30.78 & -31.23 & -23.39 \\
\hline M3h & $\mathrm{B} / \mathrm{A}$ & & 52.9 & 81.1 & -30.90 & -27.33 & -27.68 & -20.11 \\
\hline M3i & $\mathrm{B} / \mathrm{A}$ & & 53.1 & 80.2 & -34.56 & -30.79 & -31.23 & -23.39 \\
\hline M3j & $\mathrm{B} / \mathrm{A}$ & & 53.2 & 80.1 & -33.76 & -29.92 & -30.35 & -22.5 \\
\hline M3k & $\mathrm{B} / \mathrm{A}$ & & 53.0 & 80.7 & -30.97 & -27.30 & -27.68 & -20 \\
\hline M3I & $\mathrm{B} / \mathrm{A}$ & & 52.7 & 81.7 & -30.25 & -26.90 & -27.14 & -19.77 \\
\hline TS-M3aM3b & $\mathrm{B} / \mathrm{A}$ & -89.1 & 51.7 & 78.4 & -10.95 & -8.58 & -9.30 & -0.95 \\
\hline TS-M3аM3e & $\mathrm{B} / \mathrm{A}$ & -61.1 & 53.3 & 77.0 & -18.93 & -14.94 & -15.82 & -7.05 \\
\hline TS-M3aM3c & $\mathrm{B} / \mathrm{A}$ & -404.3 & 52.3 & 78.8 & -24.02 & -21.09 & -21.73 & -13.48 \\
\hline TS-M3aM3f & $\mathrm{B} / \mathrm{A}$ & -97.7 & 52.7 & 77.3 & -24.29 & -20.91 & -21.75 & -13.06 \\
\hline TS-M3bM3d & $\mathrm{B} / \mathrm{A}$ & -550.6 & 52.4 & 78.4 & -27.07 & -24.08 & -24.76 & -16.40 \\
\hline
\end{tabular}

a) B/A stands for CCSD(T)/cc-pVTZ//MP2/6-311G(d,p); B/B stands for CCSD(T)/cc-pVTZ//MP2/6-311+G(2df,2p); B/C stands for CCSD(T)/cc-pVTZ//QCISD/6-311G(d,p). b) Values in parentheses include BSSE corrections. 

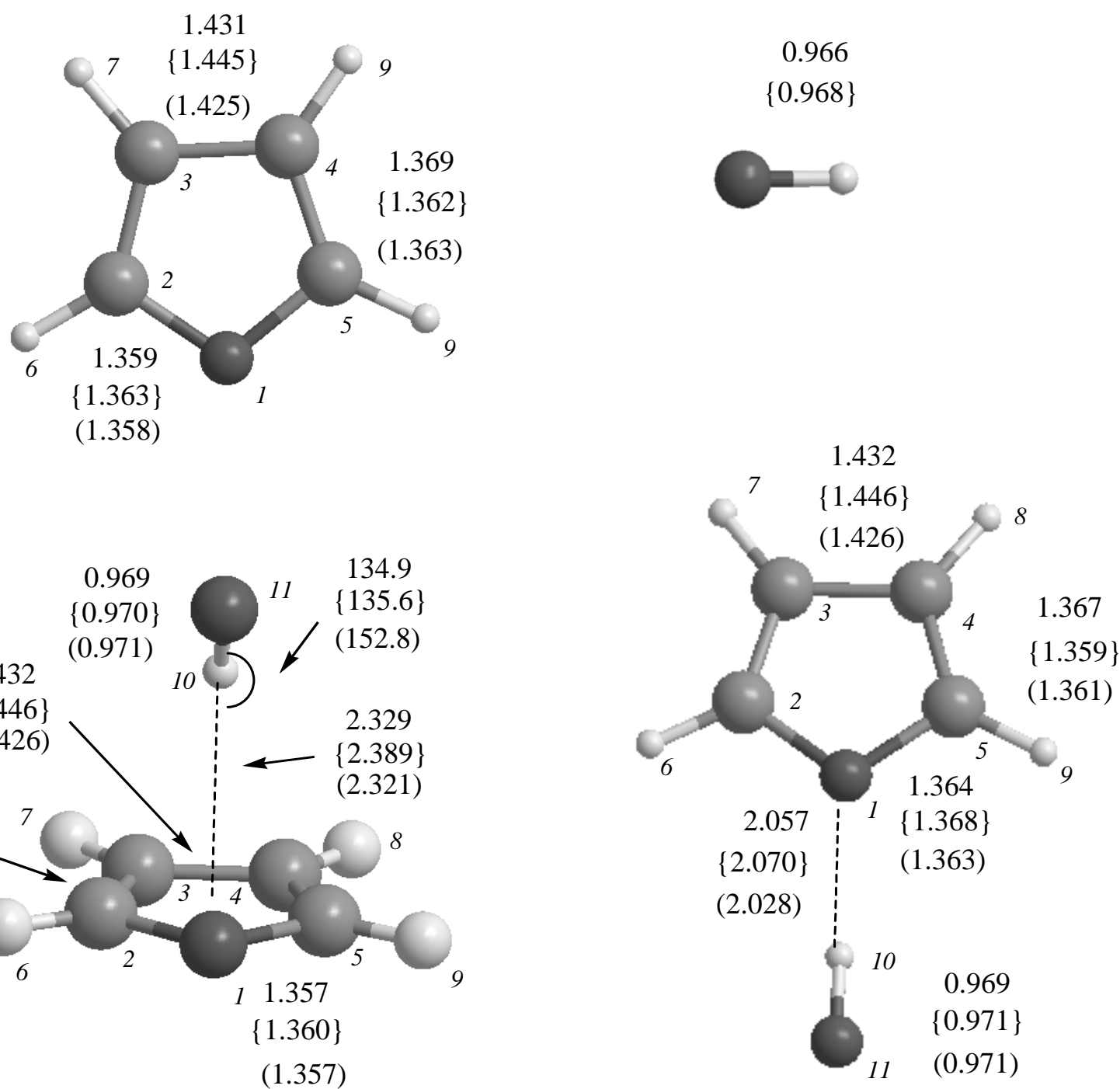

$$
\text { CR1, } C_{S}\left({ }^{2} \mathrm{~A} "\right)
$$

134.9

$\{135.6\}$

(152.8)

2.329

$\{2.389\}$

(2.321)

1.372

$\{1.363\}$

(1.366)

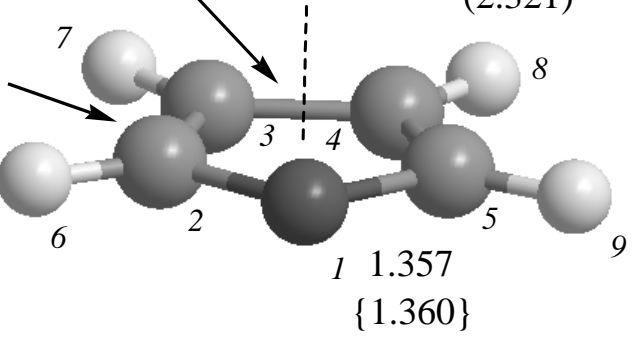

(1.357)
0.966

$\{0.968\}$

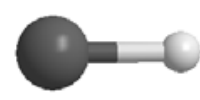

Fig. (1). Selected geometrical parameters (distances in Angstrom and angles in degrees) for the reactants and pre-reactive hydrogen bonded complexes, optimized at MP2/6-311G(d,p); QCISD/6-311G(d,p), (in brackets) and MP2/6-311+G(2df,2p), (in parentheses), levels of theory.

respectively). In the case of $\mathbf{C R} 1$, the H-bond interaction occurs with the $\pi$ system of furan and the corresponding bcp is located in the molecular symmetry plane. Moreover, it is interesting to point out that the corresponding ellipticity value is very high $(\varepsilon=61.092)$ as expected, because of the $\mathrm{OH} \cdots \pi$ interaction.

Table 2 contains the harmonic vibrational frequency of the HO stretching mode. The formation of the hydrogen bonded complexes produce a very small shift in the IR spectra, according to their small energetic stability. In the case of CR1, the shift is to the blue $\left(2.5 \mathrm{~cm}^{-1}\right)$ in a similar way as reported for other $\mathrm{X}-\mathrm{H} \cdots \pi$ interactions, whereas for CR2 a usual red shift $\left(6.5 \mathrm{~cm}^{-1}\right)$ is predicted by the calculations. The relative intensity of these modes is also computed and found to be increased by 12 and 37 times, respectively.

Table 2. Frequency $\left(\mathrm{V}\right.$ in $\left.\mathrm{cm}^{-1}\right)$ and Intensity (Int. in $\mathrm{km} . \mathrm{mol}^{-1}$ ) of the HO Stretching in the Hydrogen Bonded Complexes, Computed at QCISD/6-311G(d,p) Level of Theory

\begin{tabular}{|c|c|c|c|}
\hline & HO $\left(\mathbf{X}^{2} \boldsymbol{\Pi}\right)$ & $\mathbf{C R 1}\left({ }^{2}{ }^{*}{ }^{*}\right)$ & CR2 $\left.{ }^{2}{ }^{2} \mathbf{B}_{2}\right)$ \\
\hline \hline $\mathbf{v}^{\text {a }}$ & 3791.1 & $3793.6(2.5)$ & $3784.6(-6.5)$ \\
\hline Int. $^{\text {b }}$ & 4.2 & $51.1(12.2)$ & $155.1(36.9)$ \\
\hline
\end{tabular}

a) Values in parenthesis are frequency shifts relative to HO radical.

b) Values in parenthesis are the ratios between the intensity of the complex and that of the $\mathrm{HO}$ radical. 


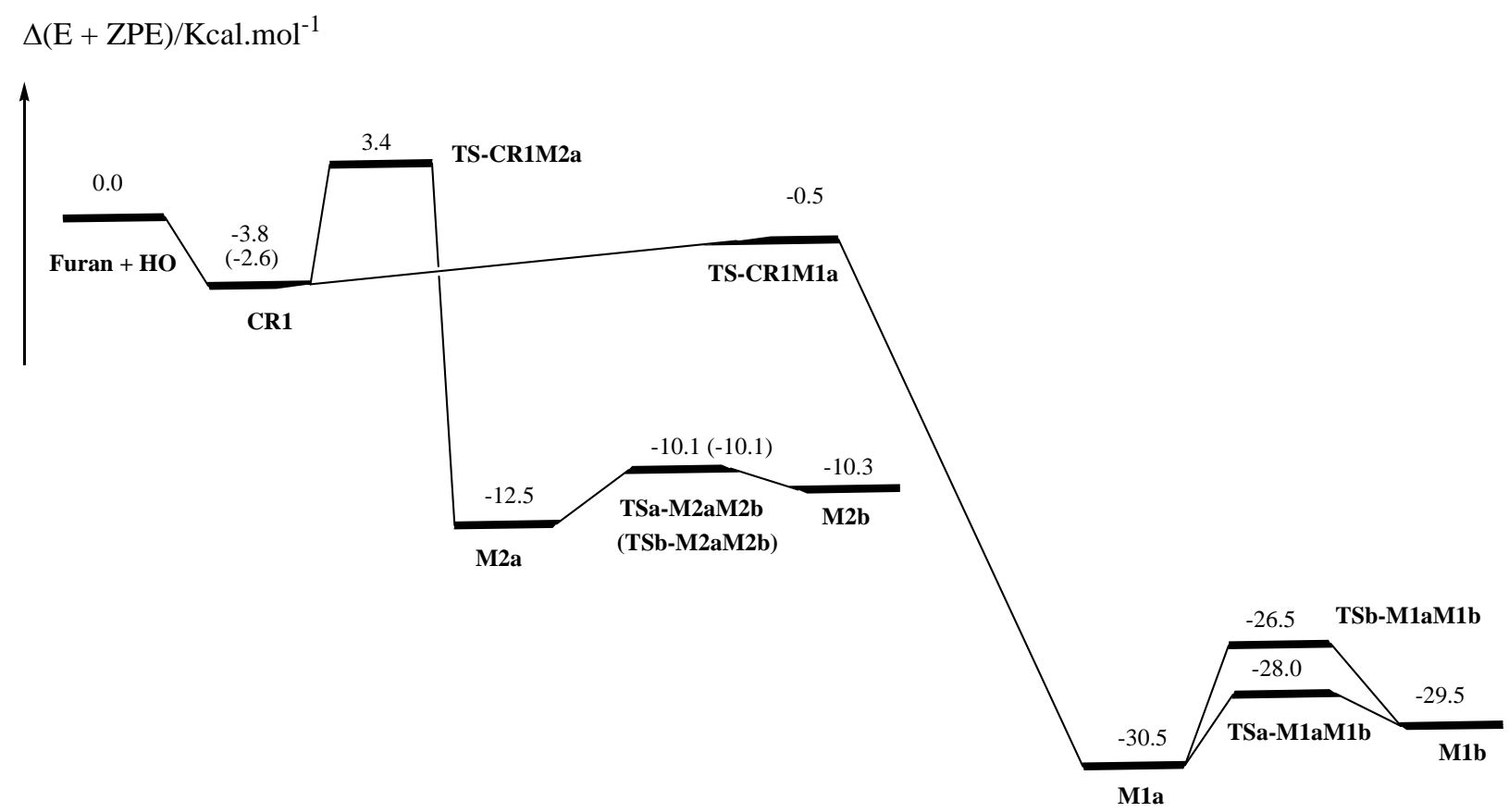

Reaction path

Fig. (2). Schematic energy diagram $\left(\Delta(\mathrm{E}+\mathrm{ZPE})\right.$ energies (in $\left.\mathrm{kcal} \cdot \mathrm{mol}^{-1}\right)$; values in parenthesis include BSSE corrections) of the potential energy surface for the formation of the 2 and 3-HO-adducts by reaction of furan with hydroxyl radical.

\section{Addition of HO Radical to Furan}

The HO radical can add to the carbon atoms 2 and 3 of furan in a process that involves the interaction between the radical of the hydroxyl and the $\pi$ system of furan. The addition occurs after the formation of the pre-reactive hydrogen bonded complex CR1, so that this is not an elementary reaction but a complex process. The formation of the 2-HOadduct (M1a) takes place through the transition state TSCR1M1a, whereas the formation of the 3-HO-adduct (M2a) occurs through the transition state TS-CR1M2a.

These two elementary reactions are the key steps in the reaction of furan with hydroxyl radical and therefore, besides the geometry optimization at MP2/6-311G(d,p) level of theory, a further geometry optimization and characterization have also been carried out for the two transition states at QCISD/6-311G(d,p) level of theory. Exhaustive calculations have also been done at MP2 and QCISD levels of theory, trying to locate further conformers of these transition states, but they were not found.

For the addition in 2 (TS-CR1M1a), Fig. (3) shows that the QCISD method predicts a larger distance between the $\mathrm{O} \cdots \mathrm{C}$ atoms of the bond that is being formed than the MP2 approach (2.109 and $1.993 \AA$, respectively), whereas the remaining geometrical parameters obtained at both levels of theory are compared quite well, with differences smaller than $0.03 \AA$. Considering the results obtained at the highest level of theory employed (QCISD), the large distance between the
$\mathrm{O} \cdots \mathrm{C}$ atoms of the bond that is being formed and the resemblance of the remaining geometrical parameters with those of furan (compare with Fig. (1)), suggest that TS-CR1M1a can be classified as an early transition state. From an electronic point of view, the $\mathrm{HO}$ radical adds to $\mathrm{C} 2$ of furan through a $\pi$ bond and this fact implies a reorganization of the $\pi$ system of the 2-HO-adduct formed, so that the resulting radical is of $\pi$ type.

The computed geometrical parameters of M1a (Fig. 3) and the AIM analysis of the corresponding wave function indicate that the $\pi$ system is delocalized among the carbons C3, C4 and C5 (the two C3C4 and C4C5 bond lengths are equal with a value of $1.378 \AA$ and the ellipticities at the corresponding bcp are 0.275 and 0.292 , which are typical values of $\pi$ bonds), whereas the $\mathrm{C} 2 \mathrm{C} 3$ bond has become a single bond (with a bond length computed to be $1.500 \AA$ ). Moreover, the analysis of the spin density shows that the unpaired electron is mainly delocalized over the C3 and C5 atoms, suggesting that a further radical reaction with the 2-HOadduct M1a would involve the C3 and/or C5 atoms. These bonding features are compatible with the resonance structures suggested by Bierbach and co-workers [13]. Furthermore, the HO group in M1a can rotate to produce the conformer M1b, both having very similar electronic features. There are two elementary pathways for this conformational change, involving a clockwise and counter-clockwise rotation of the $\mathrm{C} 2 \mathrm{O} 6$ bond respectively, and the geometrical pa- 

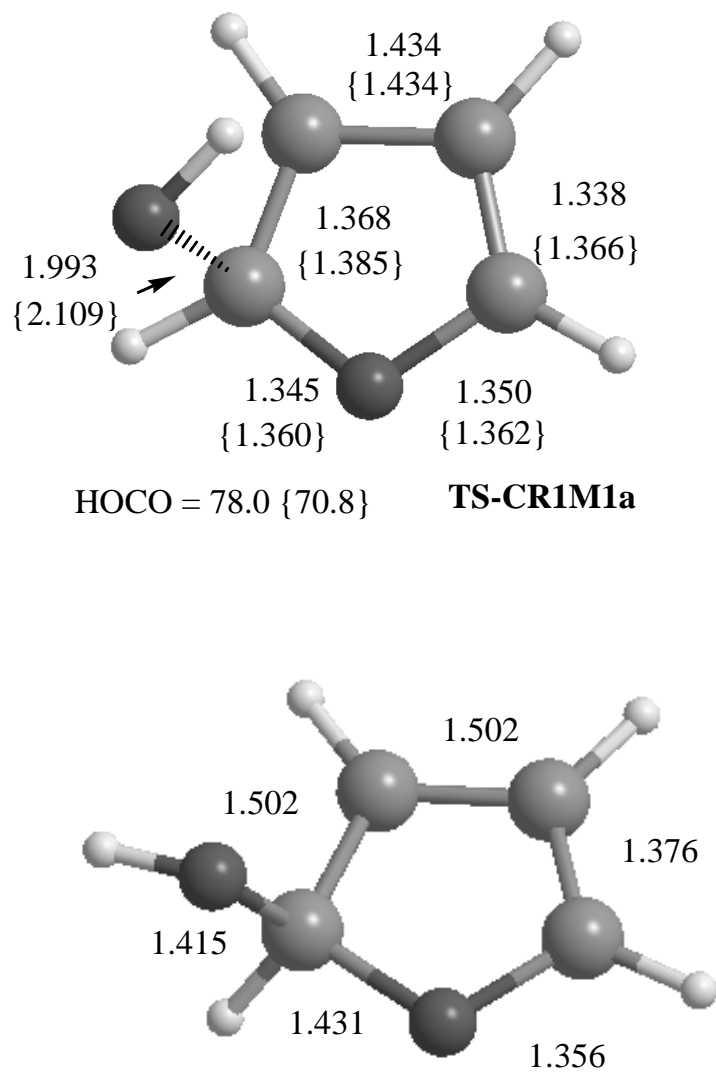

HOCO $=-160.7$

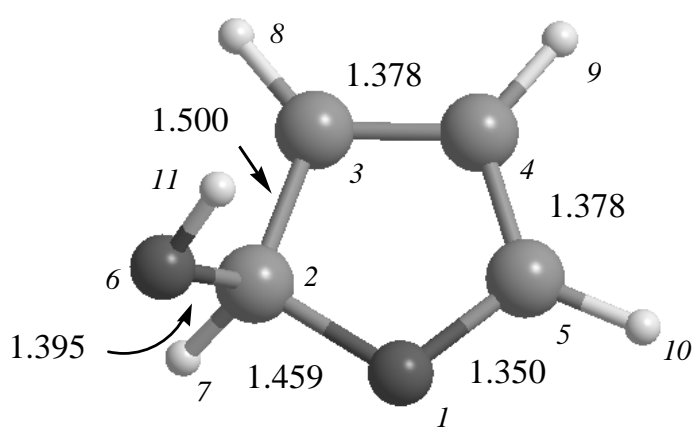

$\mathrm{HOCO}=73.6$

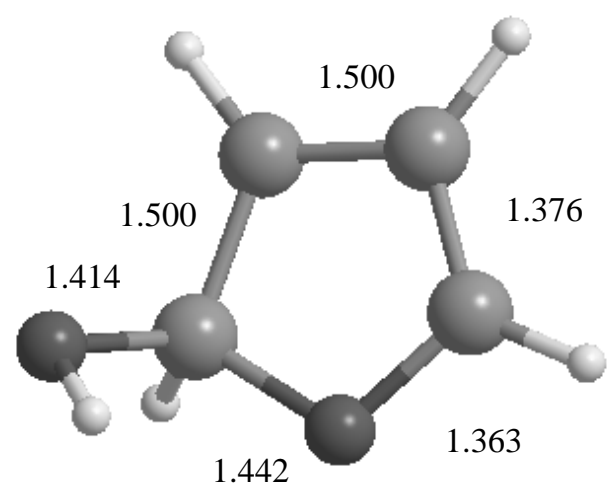

$\mathrm{HOCO}=-1.4$

TSa-M1aM1b

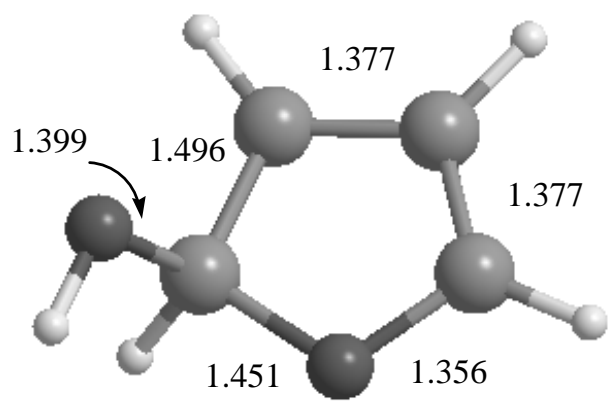

$\mathrm{HOCO}=-68.0$

M1b

Fig. (3). Selected geometrical parameters (distances in Angstrom and angles in degrees) for the stationary points involving the formation of the 2-HO-radical adduct, optimized at MP2/6-311G(d,p) and QCISD/6-311G(d,p), (in brackets), levels of theory.

rameters of the corresponding stationary points are displayed in Fig. (3). From an energetic point of view, Table 1 and Fig. (2) show that TS-CR1M1a lies below the energy of the separate reactants and the computed activation energy, with respect to the pre-reactive CR1 complex, is $3.3 \mathrm{kcal} \cdot \mathrm{mol}^{-1}$. The calculations predict that the formation of the 2-HO- adduct M1a is exothermic by about $30 \mathrm{kcal} \cdot \mathrm{mol}^{-1}(\Delta(\mathrm{E}+\mathrm{ZPE})$ value). The conformer M1b of the 2-HO-adduct is only 1 $\mathrm{kcal} \cdot \mathrm{mol}^{-1}$ higher in energy than M1a and the energy barrier for the inter-conversion between conformers is $1.5 \mathrm{kcal} \cdot \mathrm{mol}^{-1}$. Consequently, it can be concluded that both conformers (M1a and M1b) will be populated. 

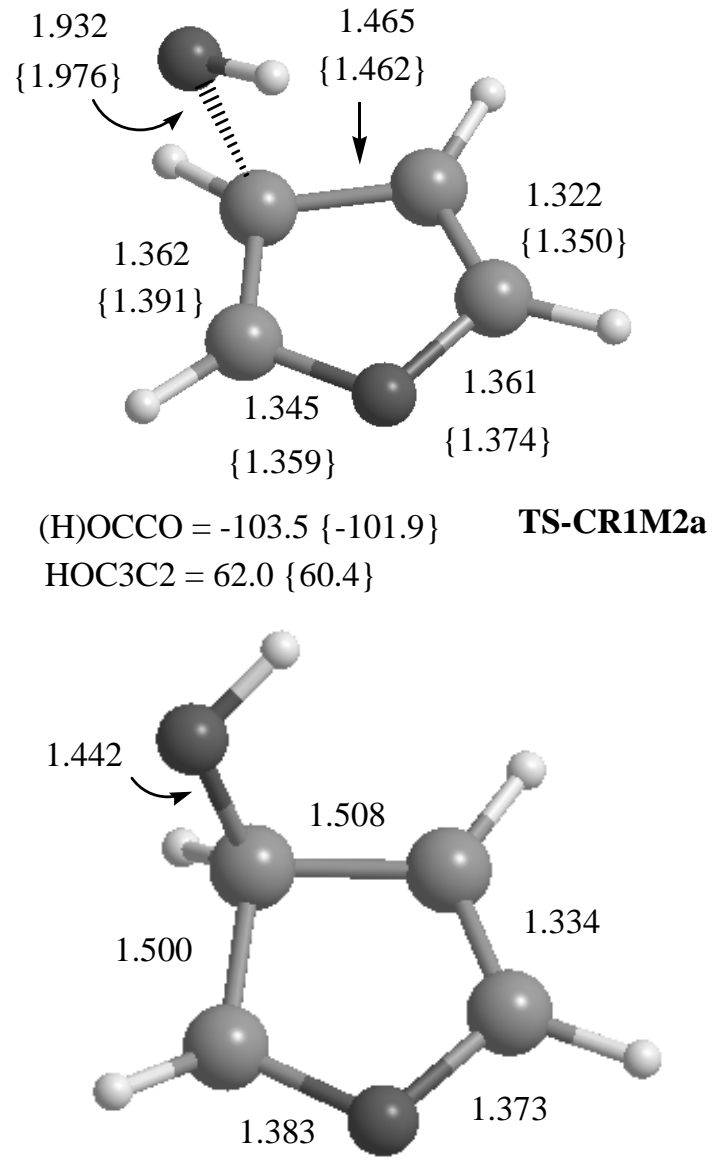

HOC2C3 $=136.2$

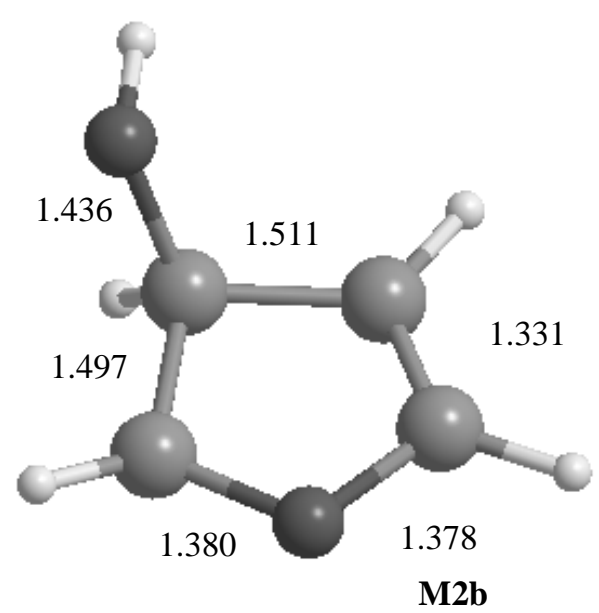

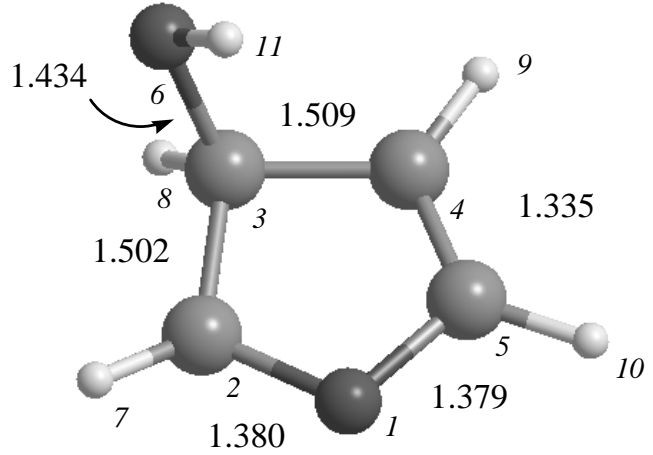

$(\mathrm{H}) \mathrm{OCCO}=-109.4$
HOC3С2 $=61.9$

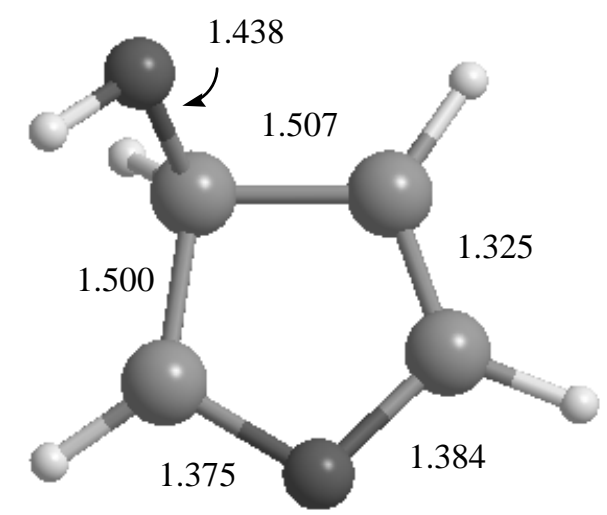

HOC2C3 $=-26.7$

TSb-M2aM2b

Fig. (4). Selected geometrical parameters (distances in Angstrom and angles in degrees) for the stationary points involving the formation of the 3-HO-radical adduct, optimized at MP2/6-311G(d,p) and QCISD/6-311G(d,p), (in brackets), levels of theory.

The addition in 3 leads to the formation of the 3-HOadduct M2a. Fig. (4) shows that at the transition state (TSCR1M2a), the bond length of the $(\mathrm{H}) \mathrm{O} \cdots \mathrm{C}$ bond that is being formed is shorter $(1.976 \AA)$ than the corresponding length found in the transition state for the addition in 2 (TSCR1M1a), discussed above, so that TS-CR1M2a can be classified as a late transition state. In this case, the process involves only the break down of the $\mathrm{C} 2 \mathrm{C} 3 \pi$ bond of furan, a fact that is reflected in the geometrical parameters of the 3HO-adduct M2a. The $\mathrm{C} 2 \mathrm{C} 3$ and $\mathrm{C} 3 \mathrm{C} 4$ are single bonds with a bond length close to $1.5 \AA$, whereas $\mathrm{C} 4 \mathrm{C} 5$ is a double bond with a computed distance of $1.335 \AA$ (see Fig. 4). As in the case of 2-HO- adduct discussed above, the HO group can rotate, producing the conformer $\mathbf{M 2 b}$. Again there are two elementary paths for this conformational change that occur through a clockwise or counter-clockwise rotation of the 


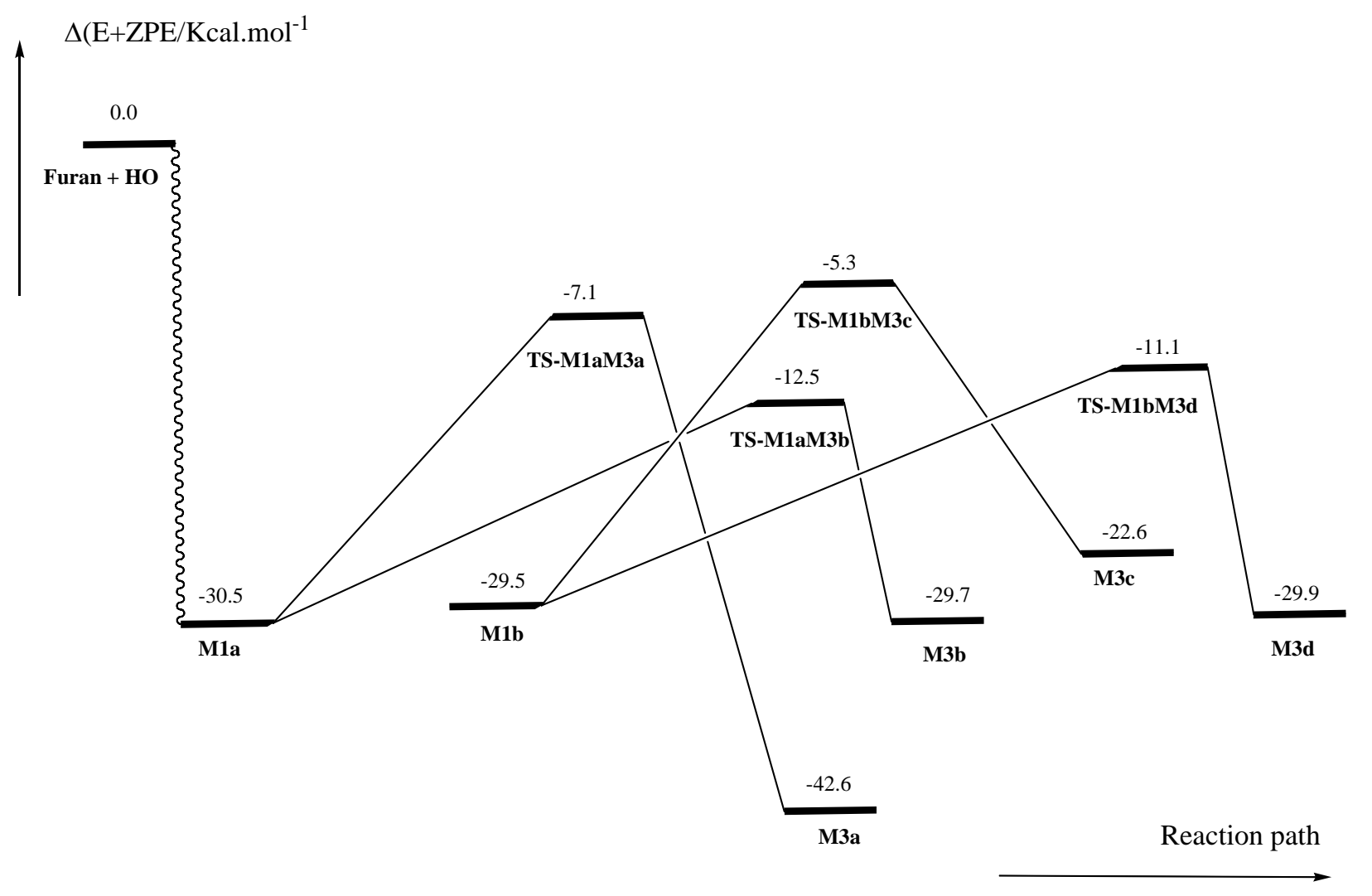

Fig. (5). Schematic energy diagram $\left(\Delta(\mathrm{E}+\mathrm{ZPE})\right.$ energies (in $\left.\mathrm{kcal} \cdot \mathrm{mol}^{-1}\right)$; values in parenthesis include BSSE corrections) of the potential energy surface for the ring opening process of formation of the 2-HO-adduct.

$\mathrm{C} 3 \mathrm{O} 6$ bond and the corresponding geometrical parameters are displayed in Fig. (4). From an energetic point of view, Table 1 and Fig. (2) show that the activation energy, with respect to the pre-reactive hydrogen bonded complex CR1, is computed to be $7.2 \mathrm{kcal} \cdot \mathrm{mol}^{-1}$. The $3-\mathrm{HO}$-adduct M2a is computed to be $12.5 \mathrm{kcal} \cdot \mathrm{mol}^{-1}$, more stable than the sum of the energies of the separate reactants. Table 1 and Fig. (2) also show that the conformer M2a is $2.2 \mathrm{kcal} \cdot \mathrm{mol}^{-1}$, more stable than M2b and the energy barrier for this conformational change is very small. At this point it is also worth noting out that the 2-HO-adduct M1a is about $18 \mathrm{kcal} \cdot \mathrm{mol}^{-1}$ more stable than the 3-HO-adduct M2a, because of the $\pi$ features of the 2-HO-adduct, which produce a stabilization effect. Moreover, the energy barrier for the formation of the 3 -HO-adduct is about $4 \mathrm{kcal} \cdot \mathrm{mol}^{-1}$ higher than that computed for the formation of the 2-HO-adduct, so it can be concluded that the 3-HO-adduct will not be formed.

\section{Ring-Opening of the 2-HO-Adduct}

There are two reaction pathways for the electrocyclic ring-opening of each of the two conformers (M1a and M1b) of the 2-HO-adduct, producing different conformers of 4hydroxybutenaldehyde radical (M3). Each elementary reaction involves the homolitic break down of the $\mathrm{O} 1 \cdots \mathrm{C} 2$ bond and the simultaneous rotation of the $(\mathrm{H}) \mathrm{OCH}$ - group, which can occur either clockwise or counter-clockwise. Fig. (5) shows a schematic energy diagram of the potential energy surface for this ring-opening process.

Starting from M1a, the reaction pathway having the lowest energy barrier goes through TS-M1aM3b and leads to the formation of $\mathbf{M 3} \mathbf{b}$. In this case, the rotation of the $(\mathrm{H}) \mathrm{OCH}-$ group is counter-clockwise. At the transition state, the $\mathrm{C} 2 \cdots \mathrm{O} 1$ bond being broken has a distance of $1.885 \AA$, the $\mathrm{C} 5 \cdots \mathrm{O} 1$ distance of the carbonyl group being formed is $1.270 \AA$, and the $\mathrm{CC}$ bond distances of the carbon skeleton have changed between 0.013 and $0.069 \AA$, with respect to the corresponding distances in the 2-HO-adduct (compare TS-M1aM3b and M1a in Figs. (6) and (3) respectively). The formation of the M3b product also involves a rearrangement of the $\pi$ system with respect to the M1a radical, as the C-C $\pi$ bond is now delocalized among the carbons C2, C3 and C4. Moreover, the unpaired electron is of $\pi$ type and mainly delocalized over the $\mathrm{C} 2$ and $\mathrm{C} 4$ atoms. This $\mathbf{M 3 b}$ radical has a planar structure $\left(C_{S}\right.$, see Fig. (6)) and is characterized by the ${ }^{2} \mathrm{~A}$ ", electronic configuration. In addition, a hydrogen bond is formed between the oxygen of the carbonyl group $(\mathrm{O} 1)$ and the hydrogen of the (H)OCH- group $(\mathrm{H} 7)$, producing a stabilization effect. The computed bond length of this hydrogen bond is $2.209 \AA$ and its nature has been confirmed by the AIM analysis (the values of $\rho_{\text {bcp }}$ and $\nabla^{2} \rho_{\text {bcp }}$ are 0.0179 and 0.0665 a.u. respectively)

Table 1 and Fig. (5) show that the calculations predict an energy barrier of $18 \mathrm{kcal} \cdot \mathrm{mol}^{-1}$, and the reaction occurs prac- 


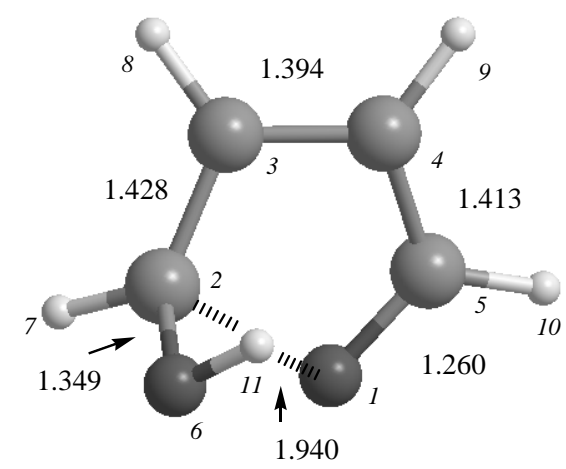

$\mathrm{OO}=2430$

TS-M1aM3a

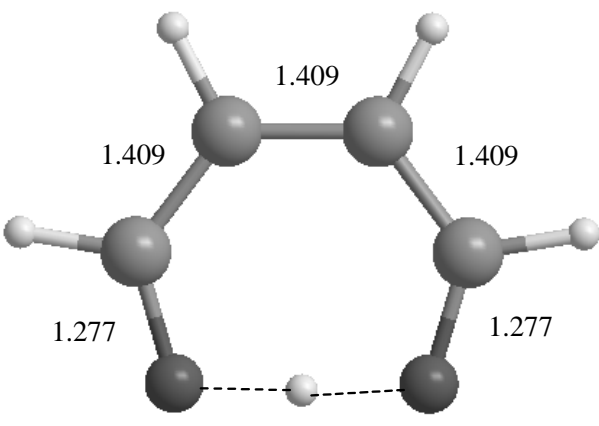

$1.190 \quad 1.190$

$\mathrm{OO}=2.377$

TS-MЗаМЗа

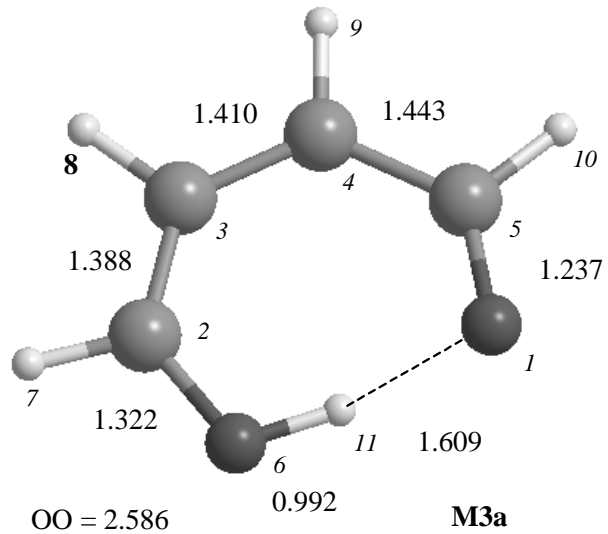

$\mathrm{OO}=2.586$
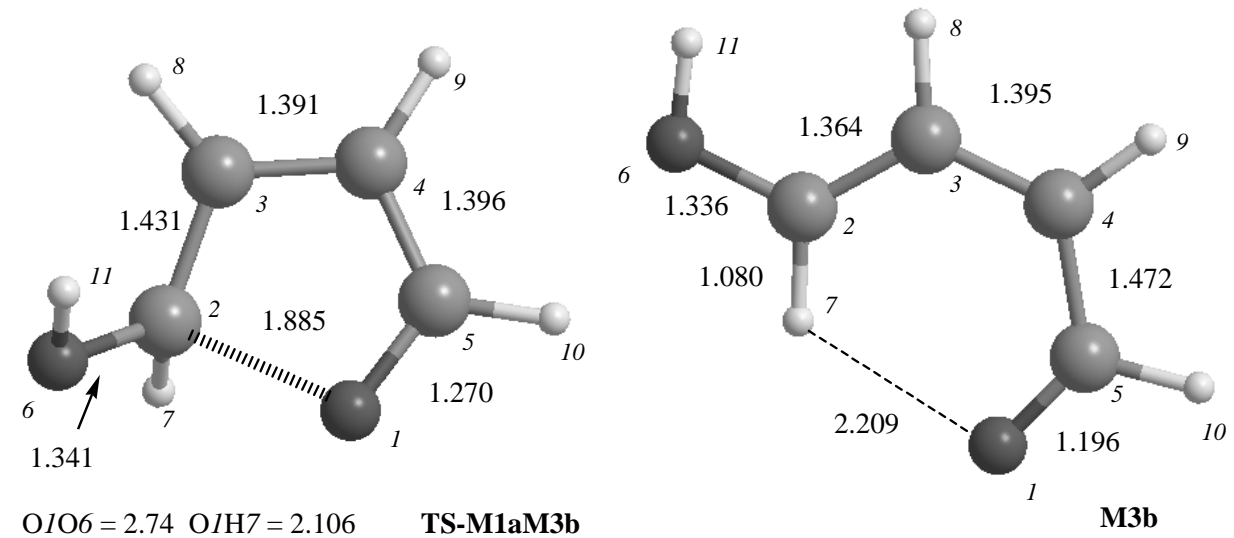

Fig. (6). Selected geometrical parameters optimized at MP2/6-311G(d,p) (distances in Angstrom and angles in degrees) for the stationary points involving the ring opening process of M1a. For M3a and TS-M3aM3a the values are obtained at QCISD/6-311G(d,p) level of theory.

tically without energy change (M3b is computed to be only $0.8 \mathrm{kcal} \cdot \mathrm{mol}^{-1}$ higher in energy than M1a).

The reaction path going through TS-M1aM3a involves a clockwise rotation and produces M3a. ${ }^{1}$ The calculations in-

\footnotetext{
${ }^{1}$ The results reported for M3a and TS-M3aM3a have been optimized and characterized at QCISD/6-311G(d,p) level of theory. The MP2 approach (also employed) predict erroneously M3a to have one imaginary frequency and TS-M3aM3a all frequencies positive.
}

dicate that, at the transition state, a considerable reorganization of the electronic structure is produced. Fig. (6) shows that the $\mathrm{C} 5 \cdots \mathrm{O} 1$ bond being broken, has a distance of 1.940 $\AA$, which is $0.06 \AA$ larger than that associated with the TSM1aM3b elementary reaction, just described. The carbonyl group is almost formed $(\mathrm{C} 2 \mathrm{O} 1=1.260 \AA)$ and the $\mathrm{CC}$ bond distances in the carbon skeleton have changed between 0.016 and $0.072 \AA$, with respect to the corresponding distances in the 

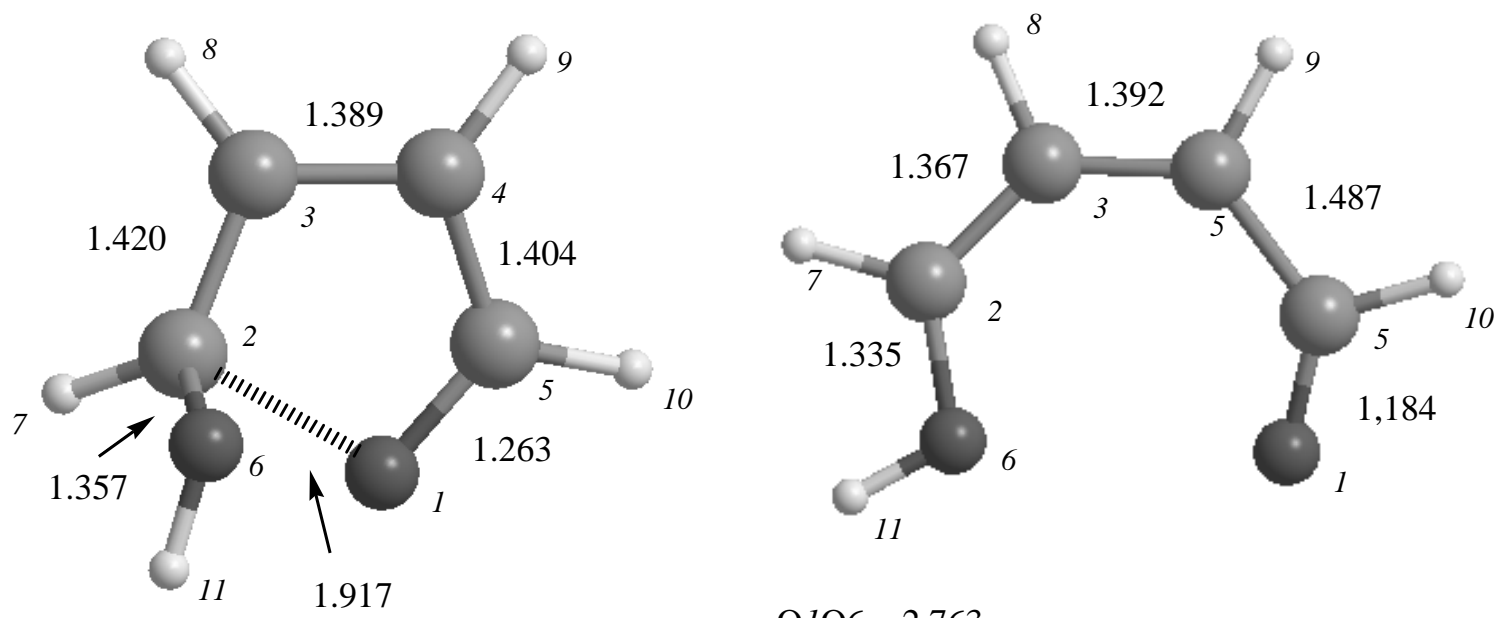

TS-M1bM3c

$\mathrm{O} 1 \mathrm{O} 6=2.763$

O1O6C2C3 $=-20.39$

M3c
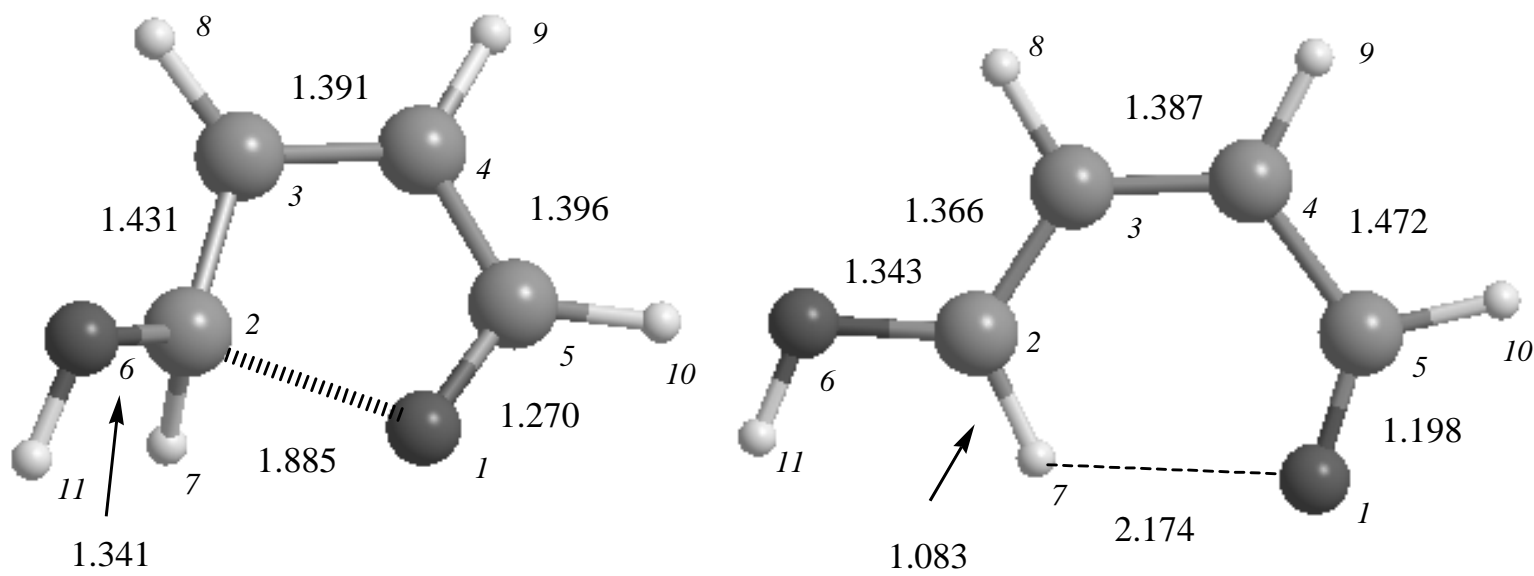

$\mathrm{O} 1 \mathrm{H} 7=2.106$

TS-M1bM3d

M3d

Fig. (7). Selected geometrical parameters optimized at MP2/6-311G(d,p) (distances in Angstrom and angles in degrees) for the stationary points involving the ring opening process of M1b.

the HO adduct (compare TS-M1aM3a and M1a in Figs. (6) and (3) respectively). Table $\mathbf{1}$ and Fig. (7) show that the computed energy barrier for this elementary reaction is 23.4 $\mathrm{kcal} \cdot \mathrm{mol}^{-1}$, which is about $5 \mathrm{kcal} \cdot \mathrm{mol}^{-1}$ higher than that of the TS-M1aM3b, described above. Note that in Fig. (3), TSM1aM3a, the distance between the two oxygen atoms is only $2.43 \AA$, suggesting a repulsive interaction between the lone pairs of the two oxygen atoms, which is responsible for the higher value of the energy barrier. The product of this elementary reaction, M3a, is the most stable conformer of the 4-hydroxy butenaldehyde radical. It has similar electronic features to $\mathbf{M 3} \mathbf{b}$ discussed above; the $\pi$ bond is delocalized among the carbons C2, C3 and C4 and the unpaired electron is of $\pi$ type and mainly delocalized over the $\mathrm{C} 2$ and $\mathrm{C} 4$ atoms. The calculations indicate that the formation of M3a from M1a is exothermic by $12.1 \mathrm{kcal} \cdot \mathrm{mol}^{-1}$, and M3a lies at $41.3 \mathrm{kcal} \cdot \mathrm{mol}^{-1}$ below the energy of the separate reactants $(\Delta(E+Z P E$ value, see Table 1$)$. It is interesting to note that M3a lies about $13 \mathrm{kcal} \cdot \mathrm{mol}^{-1}$ below $\mathbf{M 3 b}$ and therefore, it also deserves special attention. Fig. (6) shows that M3a has a planar $\left(C_{S},{ }^{2} \mathrm{~A}\right.$ ' $)$ seven member ring structure with a hydrogen bond, formed between the oxygen of the carbonyl group and the hydrogen of the HO group. The length of this hydrogen bond is computed to be $1.609 \AA$ and the AIM analysis of the wave function shows values of $\rho_{\mathrm{bcp}}$ and $\nabla^{2} \rho_{\mathrm{bcp}}$ $=0.0578$ and 0.1562 a.u., respectively. This short bond 
length suggests an easy proton transfer between the two terminal oxygen atoms, in a similar way as suggested for the $\mathrm{HO}$ oxidation of furan-2-carboxyaldehyde [25]. This process has been investigated and the product of the $\mathrm{H}$ transfer is also M3a. Fig. (6) also shows that this transition state TSM3aM3a [52], has $C_{2 V}$ symmetry $\left({ }^{2} \mathrm{~A}_{2}\right.$ electronic states) and the hydrogen being transferred is half way between the donor and acceptor oxygen atoms.

From an energetic point of view, Table 1 shows that, when the ZPE energies are taken into account, TS-M3aM3a lies below M3a, so that M3a can be classified as a low barrier hydrogen bond (LBHB). The $C_{2 V}$ structure has a lower energy than the $C_{S}$ structure, when the ZPE or even the enthalpic and entropic corrections are taken into account (see also Table 1), and this fact suggested that TS-M3aM3a should be considered as the global dynamical minimum of the $\mathbf{M 3}$ radical. The planarity of the seven member ring permits an optimum orientation of the hydrogen-oxygen interaction and allows the delocalization of the $\pi$ system all over of the carbon chain, facilitating the formation of the LBHB and explaining its high stability. This conclusion is also in line with recent results reported in the literature $[52,53]$. These electronic features are also reflected in the geometrical parameters and in the results of the AIM analysis of the corresponding wave function. All the CC bonds have typical ellipticity values of a double bond, with $\varepsilon$ values between 0.219 and 0.244 and more interestingly, the two HO bonds (H1106 and $\mathrm{H} 11 \mathrm{O} 1$ ) possess electronic features, which are typical of a covalent bond $\left(\rho_{b}=0.179\right.$ a.u.; $\nabla^{2} \rho_{b}=-0.358$ a.u. and $\mathrm{H}=$ 0.192 a.u). A similar LBHB has been recently reported in the literature for related structures such as hydrogen maleate [54] and the enolic form of acetylacetone [55], with an assigned $C_{2 V}$ structure for their minima.

Fig. (5) shows that starting from M1b, the ring opening of the HO-adduct can lead to the formation of the M3c and M3d conformers. As above, the elementary process having the lowest energy barrier involves the break down of the $\mathrm{O} 1 \mathrm{C} 2$ bond and the counter-clockwise rotation of the $\mathrm{HCOH}$ group (TS-M1bM3d, see Fig. (7)), with a computed energy barrier of $18.4 \mathrm{kcal} \cdot \mathrm{mol}^{-1}$ (see Table 1 and Fig. (5)). This elementary process occurs without a significant change of energy as M3d is computed to be only $0.4 \mathrm{kcal} \cdot \mathrm{mol}^{-1}$ lower in energy than M1b $(\Delta(E+Z P E)$ value). On the other hand, the elementary path, involving the break down of the $\mathrm{O} 1 \mathrm{C} 2$ bond and the clockwise rotation of the $\mathrm{HCOH}$ group, produces M3c and requires a higher activation energy (24.2 $\mathrm{kcal} \cdot \mathrm{mol}^{-1}$ for TS-M1bM3c, see Fig. (7)). Table $\mathbf{1}$ and Fig. (5) show that the process is computed to be endothermic by about $7 \mathrm{kcal} \cdot \mathrm{mol}^{-1}$. Moreover, it is worth pointing out that M3c and M3d are differentiated by a rotation of the $\mathrm{C} 2 \mathrm{O} 6$ bond (see Fig. 7). M3d is stabilized by a hydrogen bond interaction between $\mathrm{O} 1$ and $\mathrm{H} 7$ and the energy difference between these two conformers $\left(7.1 \mathrm{kcal} \cdot \mathrm{mol}^{-1}\right)$ allows us to qualitatively quantify the strength of this hydrogen bond interaction.<smiles>CC(=O)/C=C/C=O</smiles>

$\operatorname{M3d}\left({ }^{2} \mathrm{~A} "\right) 12.6$
TS-M3bM3d (18.5)

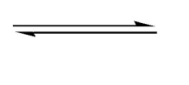

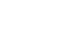

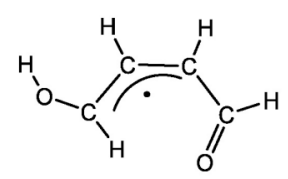

M3b $\quad\left({ }^{2} \mathrm{~A}^{\prime \prime}\right) 12.8$

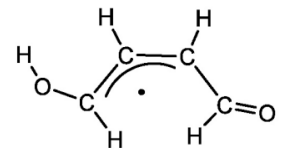

$\boldsymbol{M} 3 \boldsymbol{h}\left({ }^{2} \mathrm{~A} "\right) 15.2$<smiles>O=C/C=C/O</smiles>

$\operatorname{M3l}\left({ }^{2} \mathrm{~A}^{\prime \prime}\right) 15.7$

\section{\TS-M3аM3b (34.0)}<smiles>O=C/C=C\O</smiles>

$\operatorname{M3c} \quad\left({ }^{2} \mathrm{~A}\right) 19.9$<smiles>C=CC(C)(C)C</smiles>

M3a/TS-M3aM3a 0.0

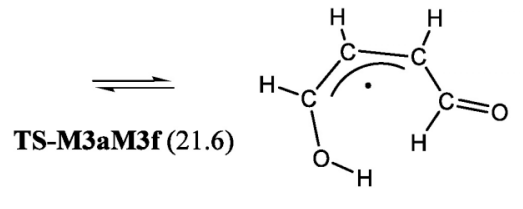

M3f $\left({ }^{2} \mathrm{~A}\right) 16.1$<smiles>O=CC=CC=CO</smiles>

M3j $\left({ }^{2} \mathrm{~A}^{\prime \prime}\right) 12.6$

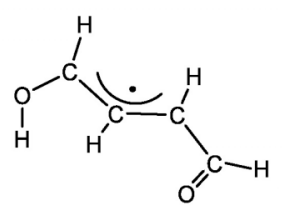

$\operatorname{M3g} \quad\left({ }^{2} \mathrm{~A}^{\prime \prime}\right) 11.8$

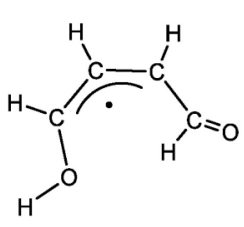

M3k $\left({ }^{2} \mathrm{~A} "\right) 15.2$

$\Downarrow$

TS-M3aM3e (27.6)

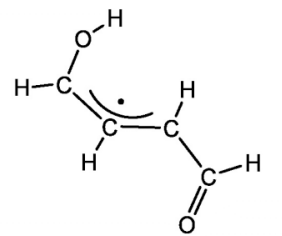

$\operatorname{M3e}\left({ }^{2} \mathrm{~A} "\right) 12.4$<smiles>O=CC=CC=O</smiles>

$M 3 i \quad\left({ }^{2} \mathrm{~A}\right) 11.8$

Scheme 1. Schematic picture of all conformers of 4-hydroxybutenaldehyde (M3) radical. The values are $\Delta(\mathrm{E}+\mathrm{ZPE})$ energies. 


\section{Conformers of the 4-Hydroxybutenaldehyde Radical (M3)}

All the different conformers of M3 have also been considered and their schematic structures are displayed in Scheme 1. It includes their relative energies as well as the energy barrier for the most significant conformational changes, which can also be derived from the results collected in Table 1. In the previous section the structure and electronic features of four of these conformers (M3a, M3b, M3c and M3d) have been discussed. It has been pointed out that M3a is the most stable conformer and the structure of TSM3aM3a is considered as the global dynamical minimum of the M3 radical. Therefore, the $\Delta(\mathrm{E}+\mathrm{ZPE})$ energy of TSM3aM3a is considered as the zero energy in Scheme 1.

As pointed out in the previous section, all the conformers of $\mathbf{M} 3$ possess a $\pi$ bond, which is mainly delocalized among $\mathrm{C} 2, \mathrm{C} 3$ and $\mathrm{C} 4$, whereas the unpaired electron occupies a $\pi$ orbital and is mainly delocalized between $\mathrm{C} 2$ and $\mathrm{C} 4$. This analysis suggests that all possible radical reactions involving these $\mathbf{M 3}$ radical conformers, would take place through the $\mathrm{C} 2$ and/or $\mathrm{C} 4$ atoms.

The results displayed in Scheme 1 indicate that taking M3a as the zero energy ( $\Delta(\mathrm{E}+\mathrm{ZPE})$ value) there are six conformers (M3b, M3d, M3e, M3g, M3i and M3j) with energies lying between 11.8 and $12.8 \mathrm{kcal} \cdot \mathrm{mol}^{-1}$, four conformers (M3f, M3h, M3k and M3I) lying between 15.2 and 16.1 $\mathrm{kcal} \cdot \mathrm{mol}^{-1}$, and one conformer, M3c, lying at $19.9 \mathrm{kcal} \cdot \mathrm{mol}^{-1}$. Besides M3a, whose high stability has been discussed above, the energetic differences among these conformers are grounded in several effects.

The AIM analysis of the corresponding wave function indicates that all conformers of the first group (M3b, M3d, M3e, M3g, M3i and M3j) possess a high value of the ellipticity for the $\mathrm{C} 4 \mathrm{C} 5$ bond ( $\varepsilon$ about 0.11 ), suggesting that the delocalization of the $\pi$ bond among $\mathrm{C} 2, \mathrm{C} 3$ and $\mathrm{C} 4$ is extended to $\mathrm{C} 5$, which produces an extra stabilization effect. Moreover, M3b and M3d present a hydrogen bond interaction between the oxygen of the carbonyl group $\mathrm{O} 1$ and $\mathrm{H} 7$, having a stabilization effect.

From the conformers of the second group, M3k also has a hydrogen bond interaction, which is formed between the oxygen of the hydroxyl group $\mathrm{O} 6$ and H10. In recent studies on gas phase radical complexes, it has been pointed out that the hydrogen bond interactions involving the oxygen atom of the carbonyl group, are more stabilizing than those involving the oxygen atom of the hydroxyl group [56,57], in the same way as occurs in these conformers.

On the other hand, M3f, M3h, and M3I are also interesting conformers. The AIM analysis of the corresponding wave function points out the existence of a bond critical point between $\mathrm{H} 10$ and $\mathrm{H} 11$ for M3f (with values of $\rho_{\mathrm{b}}=$ 0.018 a.u.; $\nabla^{2} \rho_{b}=0.056$ a.u $; H=0.0012$ a.u.) and between H10 and H7 for M3h and M3I (with values of $\rho_{b}=0.009$ a.u.; $\nabla^{2} \rho_{b}=0.034$ a.u; $H=0.0016$ a.u.), showing that there is a destabilizing $\mathrm{H}-\mathrm{H}$ interaction. For M3f, both hydrogen atoms are separated by only $1.772 \AA$, and for M3h and M3l, the two hydrogen atoms are separated by $2.193 \AA$. Such H-H interactions, with very similar electronic features, have been recently described in the literature $[45,58]$.

The last conformer M3c is computed to be the less stable. The AIM analysis of its wave function shows a bond critical point between the two oxygen atoms, indicating an interaction of a closed shell type (with values of $\rho_{\mathrm{b}}=0.013$ a.u.; $\nabla^{2} \rho_{\mathrm{b}}=0.048$ a.u; $\mathrm{H}=0.0011$ a.u) with a destabilizing effect. Similar O-O interactions have also been recently described in the literature $[57,59,60]$.

It is also worth pointing out that besides M3a, the conformers M3b, M3d, M3e, M3g, M3i and M3j are quasi degenerated with the 2-HO-adduct M1, whereas the remaining M3 conformers lie higher in energy (see Table 1).

The last point that has been considered in this work refers to the study of the most relevant conformational changes in M3. All possible conformational changes from M3a, namely to M3b (via TSM3aM3b), to M3c (via TSM3aM3c), to M3e (via TSM3aM3e) and to M3f (via TSM3aM3f), as well as M3b to M3d (via TSM3aM3d) have been investigated. Provided that almost all the M3 conformers possess similar electronic features, we can obtain a quasi quantitative estimation of the energy barriers involving all possible conformational changes in M3.

The formation of M3a from M3c involves the rotation of the $\mathrm{C}-\mathrm{O}(\mathrm{H})$ single bond and consequently the computed activation barrier is small $\left(1.6 \mathrm{kcal} \cdot \mathrm{mol}^{-1}\right)$. On the other hand, the inter-conversion between M3d and M3b occurs by the rotation of the same $\mathrm{C}-\mathrm{O}(\mathrm{H})$ single bond, and the computed activation barrier is about $5.8 \mathrm{kcal} \cdot \mathrm{mol}^{-1}$. The interconversion from M3b to M3a requires the rotation of the $\mathrm{C} 2-\mathrm{C} 3$ bond, which has a great amount of $\pi$ character. Consequently, a high energy barrier is expected and the computed results predict it to be $21.2 \mathrm{kcal} \cdot \mathrm{mol}^{-1}$. Taking into account that M3b is estimated to be extra-stabilized by about $7.1 \mathrm{kcal} \cdot \mathrm{mol}^{-1}$, because of the hydrogen bond (see the previous section), it can be estimated that the activation energy for the rotation of the $\mathrm{C} 2-\mathrm{C} 3 \pi$-bond should be $21.2-7.1=$ $14.1 \mathrm{kcal} \cdot \mathrm{mol}^{-1}$. The inter-conversion from M3e to M3a, involves the rotation of the $\mathrm{C} 3-\mathrm{C} 4$ bond, also having a considerable amount of $\pi$ character and the computed activation barrier is $15.5 \mathrm{kcal} \cdot \mathrm{mol}^{-1}$, which is close to the value estimated for the rotation of the $\mathrm{C} 2-\mathrm{C} 3$ bond. Finally the interconversion from M3f to M3a, involves the rotation of the C4-C5 bond, which is a single bond and consequently the computed activation barrier is smaller, i.e. $5.5 \mathrm{kcal} \cdot \mathrm{mol}^{-1}$.

\section{CONCLUSIONS}

The results of this investigation lead to the following important points.

1. The reaction between furan and hydroxyl radical is a complex process that involves, at first, the formation of a hydrogen bonded complex, which occurs before the addition of $\mathrm{HO}$ to the $\pi$ ring of furan. The $\mathrm{HO}$ addition can occur in positions 2 or 3 leading to the formation of the 2-HO-adduct (M1a) and 3-HO-adduct 
adduct (M2a). The pre-reactive hydrogen bonded complex is computed to be $2.6 \mathrm{kcal} \cdot \mathrm{mol}^{-1}$, more stable than the reactants, whereas the $2-\mathrm{HO}$ and $3-\mathrm{HO}-$ adducts are computed to be 30.5 and $12.5 \mathrm{kcal} \cdot \mathrm{mol}^{-1}$, respectively, more stable than the sum of the energies of furan and hydroxyl radical. In addition, conformers of M1a and M2a resulting from the rotation around (H)O-C axis, namely M1b and M2b, are also found.

2. The formation of the 2-HO-adduct (M1a) and 3-HOadduct (M2a) occurs through the transition states TSCR1M1a and TS-CR1M2a, respectively. The calculations predict TS-CR1M1a to lie $0.5 \mathrm{kcal} \cdot \mathrm{mol}^{-1}$ below the energy of the separate reactants, whereas TSCR1M2a is computed to be $3.4 \mathrm{kcal} \cdot \mathrm{mol}^{-1}$, higher in energy than furan plus hydroxyl radical. These results suggest that the 3-HO-adduct M2a will not be formed.

3. The next step is the ring opening of the 2-HO-adduct (M1a and M1b), producing different conformers of 4-hydroxybutenaldehyde radical (M3). There are two elementary reactions for each of the M1a and M1b conformers, which involve the homolitic break down of the $\mathrm{O} 1 \cdots \mathrm{C} 2$ bond and the simultaneous rotation of the $(\mathrm{H}) \mathrm{OCH}-$ group. This rotation occurs either clockwise or counter-clockwise. In each case, the reaction path, having the lowest energy barrier (about $18 \mathrm{kcal} \cdot \mathrm{mol}^{-1}$ ), is associated with the counterclockwise rotation, whereas those elementary reactions involving a clockwise rotation need to surmount a higher energy barrier of about $24 \mathrm{kcal} \cdot \mathrm{mol}^{-1}$.

4. All conformers of the 4-hydroxybutenaldehyde radical (M3), have been investigated. The most stable presents a symmetric $\left(C_{2} ;{ }^{2} \mathrm{~A}_{2}\right)$ seven member ring structure, having a low barrier hydrogen bond and a $\pi$ bond delocalization along all the carbon structure. This conformer is predicted to be about $43 \mathrm{kcal} \cdot \mathrm{mol}^{-1}$, more stable than the separate reactants. The remaining conformers of M3 lie between 22 and 33 $\mathrm{kcal} \cdot \mathrm{mol}^{-1}$, below the energy of the separate reactants.

\section{ACKNOWLEDGMENTS}

The calculations described in this work were carried out at the Centre de Supercomputació de Catalunya (CESCA) and Centro de Supercomputación de Galicia (CESGA), whose services are gratefully acknowledged. The financial support for this research was provided by the Spanish Dirección General de Investigación Científica y Técnica (DGYCIT, Grant CTQ2005-07790) and by the Generalitat de Catalunya (Grant 2005SGR00111).

\section{REFERENCES}

[1] Greenberg JP, Zimmerman PR, Heidt L, Pollock W. Hydrocarbon and Carbon-Monoxide emissions from biomass burning in Brazil. Geophys Res Atmos 1984; 89: 1350-4.

[2] Isidorov VA, Zenkevich IG, Ioffe BV. Volatile Organic-compounds in the atmosphere of forests. Atmos Environ 1985; 19: 1-8.

[3] Smith RM, Okeefe PW, Aldous KM, Valente H, Connor SP, Donnelly RJ. Chlorinated dibenzofurans and dioxins in atmospheric samples from cities in New-York. Environ Sci Technol 1990; 24: 1502-6.

[4] Khalil MAK, Rasmussen RA. Forest hydrocarbon emissionsrelationships between fluxes and ambient concentrations. J Air Waste Manag Assoc 1992; 42: 810-13.

[5] Knudsen JT, Tollsten L, Bergstrom LG. Floral scents-a checklist of volatile compounds isolated by headspace techniques. Phytochemistry $1993 ; 33: 253-80$.

[6] Tuazon EC, Atkinson RA. Product study of the gas-phase reaction of isoprene with the $\mathrm{OH}$ radical in the presence of nox. Int $\mathrm{J}$ Chem Kin 1990; 22: 1221-36.

[7] Atkinson R, Aschmann SM, Tuazon EC, Arey J, Zielinska B. Formation of 3-methylfuran from the gas-phase reaction of oh radicals with isoprene and the rate constant for its reaction with the $\mathrm{OH}$ radical. Int J Chem Kin 1989; 21: 593-604.

[8] Tuazon EC, Alvarado A, Aschmann SM, Atkinson R, Arey J. Products of the gas-phase reactions of 1,3-butadiene with $\mathrm{OH}$ and NO3 radicals. Environ Sci Technol 1999; 33: 3586-95.

[9] Atkinson R. Gas-phase tropospheric chemistry of Organiccompounds. J Phys Chem Ref Data Monograph 2 1994; 1- 216.

[10] Paulson SE, Flagan RC, Seinfeld JH. Atmospheric photooxidation of isoprene part II: the ozono-isoprene reaction. Int J Chem Kin 1992; 24: 103-25.

[11] Francisco-Marquez M, Alvarez-Idaboy JR, Galano A, VivierBunge A. A possible mechanism for furan formation in the tropospheric oxidation of dienes. Environ Sci Technol 2005; 39: 8797802.

[12] Atkinson R, Aschmann SM, Carter WPL. Kinetics of the reactions of O-3 and $\mathrm{OH}$ radicals with furan and thiophene at $298+/-2 \mathrm{~K}$. Int J Chem Kin 1983; 15: 51-61.

[13] Bierbach A, Barnes I, Becker KH. Product and kinetic-study of the $\mathrm{OH}$-initiated gas-phase oxidation of furan, 2-methylfuran and furanaldehydes at approximate-to-300 K. Atmos Environ 1995; 29: 2651-60.

[14] Bierbach A, Barnes I, Becker KH, Wiesen E. Atmospheric chemistry of unsaturated carbonyls-butenedial, 4-oxo-2-pentenal, 3hexene-2,5-dione, maleic-anhydride, 3h-furan-2-one, and 5-methyl3H-furan-2-one. Environ Sci Technol 1994; 28: 715-29.

[15] Bierbach A, Barnes I, Becker KH. Rate coefficients for the gasphase reactions of hydroxyl radicals with furan, 2-methylfuran, 2ethylfuran and 2,5-dimethylfuran at 300+/-2-K. Atmos Environ 1992; 26: 813-17.

[16] Bierbach A, Barnes I, Becker KH. Rate constants of the Brinitiated gas-phase oxidation of a series of alcohols, furans and benzenes at 300 +/- 2 K. Atmos Environ 1999; 33: 2981-92.

[17] Villanueva F, Barnes I, Monedero E, Salgado S, Gomez MV, Martin P. Primary product distribution from the $\mathrm{Cl}$-atom initiated atmospheric degradation of furan: Environmental implications. Atmos Environ 2007; 41: 8796-810.

[18] Cabanas B, Villanueva F, Martin P, Baeza MT, Salgado S, Jimenez E. Study of reaction processes of furan and some furan derivatives initiated by $\mathrm{Cl}$ atoms. Atmos Environ 2005; 39: 1935-44.

[19] Grosjean D, Williams EL. Environmental persistence of organiccompounds estimated from structure reactivity and linear freeenergy relationships unsaturated aliphatics. Atmos Environ 1992; 26: 1395-405.

[20] Atkinson R, Aschmann SM. Kinetics of the gas-phase reaction of $\mathrm{Cl}$ atoms with a series of organics at $296+/-2 \mathrm{~K}$ and atmosphericpressure. Int J Chem Kin 1985; 17: 33-41.

[21] Atkinson R. Kinetics and mechanisms of the gas-phase reactions of the hydroxyl-radical with organic compounds. J Phys Chem Ref Data Monograph 1 1989; 1-246.

[22] Kind I, Berndt T, Boge O, Rolle W. Gas-phase rate constants for the reaction of NO3 radicals with furan and methyl-substituted furans. Chem Phys Lett 1996; 256: 679-83.

[23] Bierbach A, Barnes I, Becker KH. Rate coefficients for the gasphase reactions of bromine radicals with a series of alkenes, dienes, and aromatic hydrocarbons at 298+/-2 K. Int J Chem Kin 1996; 28: 565-77.

[24] D'Angelantonio M, Emmi SS, Poggi G, Beggiato G. Reaction of the $\mathrm{OH}$ radical with furfural. Spectral and kinetic investigation by pulse radiolysis and by ab initio and semiempirical methods. J Phys Chem A 1999; 103: 858-64.

[25] Emmi SS, D'Angelantonio M, Poggi G, Russo M, Beggiato G, Larsen B. The selective $\mathrm{OH}$ radical oxidation of sorbitylfurfural: A 
combined experimental and theoretical study. J Phys Chem A 2002; 106: 4598-607.

[26] Zhang WC, Du B, Mu LL, Feng CJ. Mechanism for the gas-phase reaction between $\mathrm{OH}$ and 3-methylfuran: A theoretical study. Int $\mathrm{J}$ Quant Chem 2008; 108: 1232-8.

[27] Zhang WC, Du BN, Mu LL, Feng CJ. Computational study on the mechanism for the reaction of $\mathrm{OH}$ with 2-methylfuran. J Mol Struct Theochem 2008; 851: 353-7.

[28] Krishnan R, Binkley JS, Seeger R, Pople JA. Self-consistent molecular orbital methods. XX. A basis set for correlated wave functions. J Chem Phys 1980; 72: 650-4.

[29] Moeller C, Plesset MS. Note on an approximation treatment for many-electron systems. Phys Rev 1934; 46: 618-22.

[30] Frisch MJ, Head-Gordon M, Pople JA. Semi-direct algorithms for the MP2 energy and gradient. Chem Phys Lett 1990; 166: 281-9.

[31] Head-Gordon M, Head-Gordon T. Analytic MP2 frequencies without fifth-order storage. Theory and application to bifurcated hydrogen bonds in the water hexamer. Chem Phys Lett 1994; 220: 122-8.

[32] Pople JA, Head-Gordon M, Raghavachari K. Quadratic configuration interaction. A general technique for determining electron correlation energies. J Chem Phys 1987; 87: 5968-75.

[33] Cizek J. On the correlation problem in atomic and molecular systems. calculation of wavefunction components in ursell-type expansion using quantum-field theoretical methods. J Chem Phys 1966; 45: 4256-66.

[34] Lee YS, Kucharski SA, Bartlett RJA. Coupled Cluster approach with triple excitations. J Chem Phys 1984; 81: 5906-12.

[35] Purvis GD, Bartlett RJA. Full coupled-cluster singles and doubles model-the inclusion of disconnected triples. J Chem Phys 1982; 76: 1910-18.

[36] Dunning THJ. Gaussian basis sets for use in correlated molecular calculations. I. The atoms boron through neon and hydrogen. J Chem Phys 1989; 90: 1007-23.

[37] Kendall RA, Dunning TH, Harrison RJ. Electron-affinities of the 1 st-row atoms revisited-systematic basis-sets and wave-functions. J Chem Phys 1992; 96: 6796-806.

[38] Rienstra-Kiracofe JC, Allen WD, Schaefer III HF. The C2H5 + O2 reaction mechanism: High level ab-initio characterizations. J Phys Chem A 2000; 104: 9823-40.

[39] Lee TJ, Taylor PR. A diagnostic for determining the quality of single-reference electron correlation method. Int J Quantum Chem Symp 1989; 23: 199 -203.

[40] Boys SF, Bernardi F. The calculation of small molecular interactions by the differences of separate total energies. Some procedures with reduced errors. Mol Phys 1970; 19: 553-66.

[41] Frisch MJ, Trucks GW, Schlegel HB, et al. Gaussian 03, Revision C.01 Gaussian, Inc.: Wallingford CT; 2004.

[42] Shaftenaar G, Noordik JH. Molden: a pre- and post-processing program for molecular and electronic structures. J Comput Aid Mol Des 2000; 14: 123-34.
[43] Bader RFW. Atoms in Molecules. A Quantum theory. Clarendon Press: Oxford; 1995

[44] Bader RFW. AIMPAC program. Downloaded May 2002: Available from: http://www.chemistry.mcmaster.ca/aimpac.

[45] Popelier PLA. Characterization of a dihydrogen bond on the basis of the electron density. J Phys Chem A 1998; 102: 1873-8.

[46] Kraka E, Cremer D. Chemical implication of local features of the electron density distribution. In: maksic zb, ed. theoretical models of chemical bonding. The concept of the chemical bond, SpringerVerlag, Heidelberg, 1990; vol. 2: pp. 452- 542.

[47] Bader RFW, Popelier PLA, Keith TA. Theoretical definition of a functional-group and the molecular-orbital paradigm. Angew Chem Int Ed Engl 1994; 33: 620- 31.

[48] Koch U, Popelier PLA. Characterization of C-H-O Hydrogen bonds on the basis of the charge density. J Phys Chem 1995; 99: 9747-54.

[49] Hobza P, Havlas Z. Blue-shifting hydrogen bonds. Chem Rev 2000; 100: 4253-64.

[50] Joseph J, Jemmis ED. Red-, blue-, or no-shift in hydrogen bonds: A unified explanation. J Am Chem Soc 2007; 129: 4620-32.

[51] Heidrich D. Do isopropyl and tert-butyl cations form pi complexes with benzene? Angew Chem Int Ed Engl 2002; 41: 3208-10.

[52] Sanz P, Yáñez M, Mó O. Resonance-assisted intramolecular chalcogen- chalcogen interactions? Chem Eur J 2003; 9: 4548-55.

[53] Sanz P, Mo O, Yanez M, Elguero J. Non-resonance-assisted hydrogen bonding in hydroxymethylene and aminomethylene cyclobutanones and cyclobutenones and their nitrogen counterparts. Chemphyschem 2007; 8: 1950-8.

[54] Woo H-K, Wang X-B, Wang L-S. Probing the Low-Barrier Hydrogen Bond in Hydrogen Maleate in the Gas Phase: A Photoelectron Spectroscopy and ab Initio Study. J Phys Chem A 2005; 109: 10633-37.

[55] Caminati W, Grabow JU. The C-2v structure of enolic acetylacetone. J Am Chem Soc 2006; 128: 854-7.

[56] Torrent-Sucarrat M, Anglada JM. On the gas phase hydrogen bond complexes between formic acid and hydroperoxyl radical. a theoretical study. J Phys Chem A 2006; 110: 9718-26.

[57] Torrent-Sucarrat M, Anglada JM. The Gas-phase hydrogen bond complexes between formic acid with hydroxyl radical: A theoretical study. Chemphyschem 2004; 5: 183 -91

[58] Matta CF, Hernandez-Trujillo J, Tang TH, Bader RFW. Hydrogenhydrogen bonding: A stabilizing interaction in molecules and crystals. Chem Eur J 2003; 9: 1940-51.

[59] Bofill JM, Olivella S, Solé A, Anglada JM. The Mechanism of methoxy radical oxidation by $\mathrm{O}_{2}$ in the gas phase. computational evidence for direct $\mathrm{H}$ atom transfer assisted by intermolecular noncovalent $\mathrm{O} \cdots \mathrm{O}$ bonding interaction. J Am Chem Soc 1999; 121: 1337-47.

[60] Zhurova EA, Tsirelson VG, Stash AI, Alan-Pinkerton A. Characterizing the oxygen-oxygen interaction in the dinitramide anion. J Am Chem Soc 2002; 124: 4574-5. 